\title{
A TRIAL TO COLLECT STUDENTS' RESPONCES USING A CELLULAR PHONE IN TEACHING CLASSES
}

\author{
Akinobu ANDO*, Hiraku ABIKO*, Makoto KINEFUTI** \\ *Miyagi University of Education, **Hokkaido University of Education, JAPAN \\ \{andy, abiko\}@staff.miyakyo-u.ac.jp,kinefuti@sap.hokkyodai.ac.jp
}

\begin{abstract}
We present the system and the method to support two-way communication using a cellular phone in university classes. The architecture combines the internet, a note PC, a web server, and cellular phones to allow students to response. The teacher will be able to arrange a class suitably because he can know students' responses easily and immediately. This method adopts to use students' cellular phones to take simple questionnaire in a large class. Formerly, to question we have students raise their hands or write their concerns on paper. But it is troublesome and takes a long time to count students' raised hands. Using our system and method, we can know the result easily and immediately after students respond. It gives advantage for teachers to arrange the way to teach more suitable, because a teacher can know how much knowledge students have about a lecture.
\end{abstract}

\section{INTRODUCTION}

In this paper we describe the Mail-Method System to collect students' responses using a cellular phone while in class. In this Mail-Method System, it means the whole procedure and whole system for arranging a few simple contents only using an E-mail. Prior studies of this system suggest that it is useful and convenient to collect and display a lot of persons' comments in a short period of time. In this paper, we discuss how we developed the function as a whole and how this system is used as a simple questionnaire in our classes.

\section{PROBLEM DESCRIPTION}

In this research, our goal was to develop technologies and actually support a kind of communication over time and places during our teaching. In this section, we first describe the nature of the method used to collect students' responses during a class; then, we provide an overview of our approach to this problem; finally we discuss several cases in which this system was used.

\section{Collecting Students' Responses}

In the 1970s, the schools in Japan were active in attempting to grasp students' study situation. Therefore, there was equipment called an "Answer checker" to help with reaction analysis (analyzer) [1]. It was special equipment with which a lot of switches are located in a line with a student's desk.
Students push these switches in response to the teacher's question. Then, the monitor on a teacher's desk displayed the total result of the pushed switches. Although this had an introductory high cost, the educational effect was accepted (uniquely in the conservative world of education), and many schools equipped themselves with it.

In recent years, the tendency of individualization of study has become strong again. Instead of the specialized and/or expensive previous equipment, using a common computer we can participate in classes more easily. To realize a student's readiness and a student's studying situation is very important information when a teacher wants to advance instruction [2]. Though the system is computerized, recognizing students' responses require students to have their own input equipment. Consequently, it was difficult to use the analysis equipment daily.

At a university, a teacher gives a lecture in many cases in front of many students in a large classroom. The contents of a lecture are various. Therefore, some teachers often tend not to encourage two-way communication between the students and the teachers. The teachers say that the problem is that students aren't able to understand the lecture by themselves. However, is that the only problem? Is it good that classes tend to become places of "giving and receiving information."? If a university teacher can understand them, a teacher will be able to change how to explain without changing the contents of a lecture. Our assumption is that it is effective to encourage students in studies so even a 
university teacher knows how much the students can grasp.

\section{Overview of Current Method}

Formerly there were two approaches for this problem. The one approach is "letting students raise their hands", another approach is "letting students write their concerns on paper". The approach that we suggest is different from a conventional one in the two following points. "Letting students write their concerns on paper" means that when a teacher asks students questions they raise a hand to answer. A teacher treats the result by counting the number of raised hands (sometimes by their impression) This approach is very simple and takes neither specialized equipment nor cost, but if there are many students it will be difficult for the teacher to decide and will take a long time if the teacher counts the numbers accurately. Furthermore, this is unsuitable to analyze in detail because it is hard to record; for example, who raised a hand or not.

The second approach is "write their concerns on paper". This does not need description and can be executed easily, too. It is possible to analyze in detail because papers which are written by students are kept as a record. However, it is unsuitable when a teacher wants to take advantage of an effect immediately because it is troublesome and take a long time to collect the papers and to add them up. Our proposal as the third approach is to use students' cellular phone or PHS, instead of the aforesaid two approaches [3]. According to our preliminary survey, the possession rate of a cellular phones or PHS is almost 100percent among students. As one of the advantages, a teacher doesn't have to explain the operation because they have already used them.

\section{Determination of the Transmitting Method}

We determined to use e-mail due to the subsequent points. There are three approaches which a student can transmit information using a cellular phone. The first is to use e-mail, the second is to fill in the form on a web page, and the third is to communicate with a server computer using a JAVA application. According to an investigation of a function of students' cellular phones, all of them have e-mail functions, 88.2 percent of them have a web browser, and 60.6 percent have JAVA technology (Figure 1). Thus we compared the input time between using e-mail and using a web-browser (Figure 2). According to this figure, it is understandable that the web-browsing-mode needs more time than the e-mail mode because it takes a long time until input page is displayed.

In addition, the e-mail mode can be shown to be more effective in the following four points. The first, e-mail is cheaper regarding packet tariffs and needs shorter time than web-browsing. The reason is because in using the web we have to download a lot of data from a server computer.

The second, e-mail operation has a similarity among different models of cellular phones. Figure 3 shows that the displayed image is not same with respect to the capacity of cellular phones.

The third, a teacher can't use it spontaneously because he

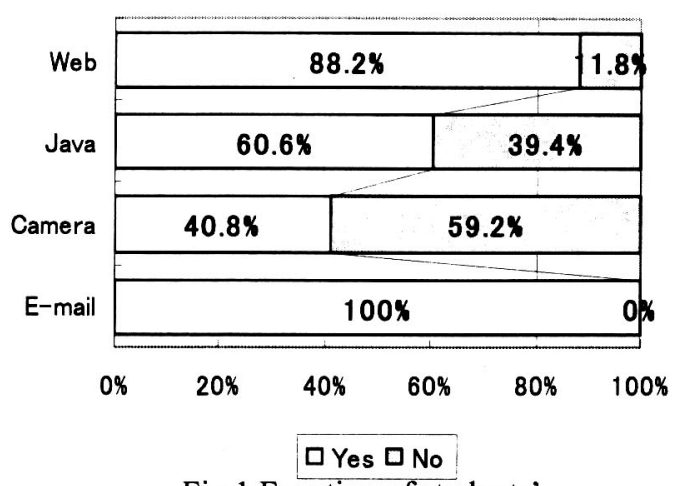

Fig. 1 Function of students' Cellular Phone

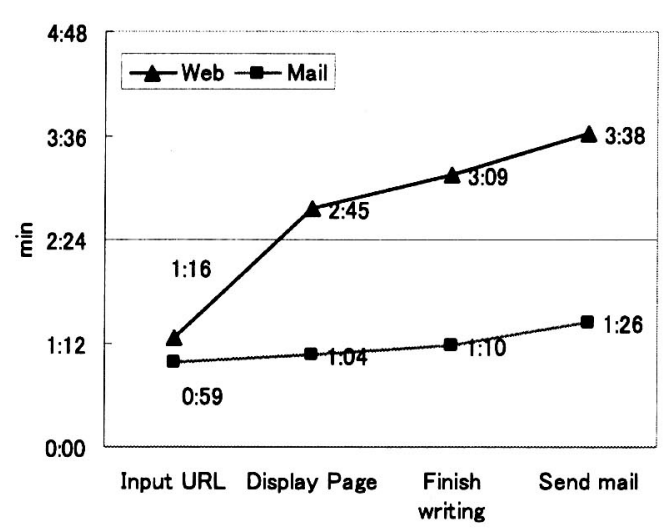

Fig.2 Compare Web with Mail

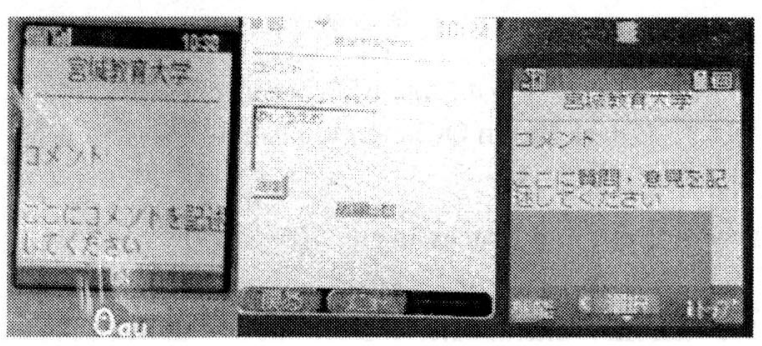

Fig.3 Differences of a screen (same contents) 
has to think about questions and make a web-page beforehand. The last reason is that there are many students who don't have a model with web-browsing yet. In the case of using cellular phones, web-browsing has only the advantage of reducing frequency of mistakes because the students only have to fill in fixed forms on a web-page as compare to a free-response e-mail.

\section{SYSTEM IMPLEMENTATION}

\section{About Mail-Method System}

The overview of this system is shown as Figure 4. This system requires the internet, a common mail server and a web server which has been installed with the PHP script we developed. The flow of an e-mail is transmitted to indicate a result is simple in order to introduce and apply briefly. At First students write their answer in an e-mail text for the teacher. At that time the teacher has students input a fixed subject.

In order to indicate the result of the questionnaire a teacher has only to access a mail server through a web server, which has been installed to a 'Mail Method Questionnaire script'. And the teacher inputs his user ID and password. Just then all mails in the mail box are indicated as a list. Finally a result of the answers in selected mails was shown calculating all e-mails have the same subject after the target mail have been clicked. Figure4 shows the flow beginning with the teacher's question to when students' responses are displayed.

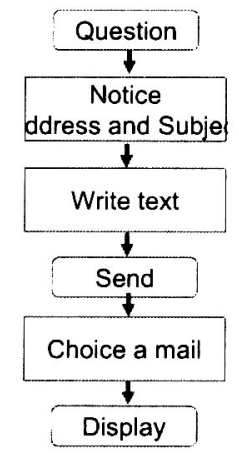

Fig.4 Flow of Procedure from Question to Display

\section{How to input and processing}

We did not attempt to explain how familiar Japanese students are with using e-mail on a cellular phone as it is well known. Almost all of them understand how to use it without being taught. Because e-mail doesn't have a fixed form, we can write text freely. On the contrary, owing to that, it is difficult for the teacher to write a fixed form text. In this case, it is important to fix a format or govern the input. Even though students are using the mail method for the first time, they should be able to input according to the rules as explained by the teacher. Therefore, the input rules are simplified. The only rule is that students send an e-mail written with their answer numbers using a space character as a delimiter. As an algorithm to choose and display selected e-mails from an e-mail server, we adopted the Mail-Method we have developed [4]. The mail-method is a simple method to choose e-mails so they have the same subject. This study describes, how we extended the function to count answers and draw a graph to the Mail-Method

\section{INITIAL PRACTICAL USE}

\section{Method}

To evaluate interactions of this system, we decided to use it in real class trial. One of the target classes is 'a study of teaching materials about technical Education'-13 participants- another is 'Information processing'-34 participants-. The task of 'a study of teaching materials about technical Education' includes an evaluation of the lecture and the collection of data. The Information Processing class has purposes to get some data. One of the data is to get the students' learning readiness of about the materials. Another one is to obtain some diagnostic information to regulate the teaching progress. To arrow them to answer, we display questions on the screen .
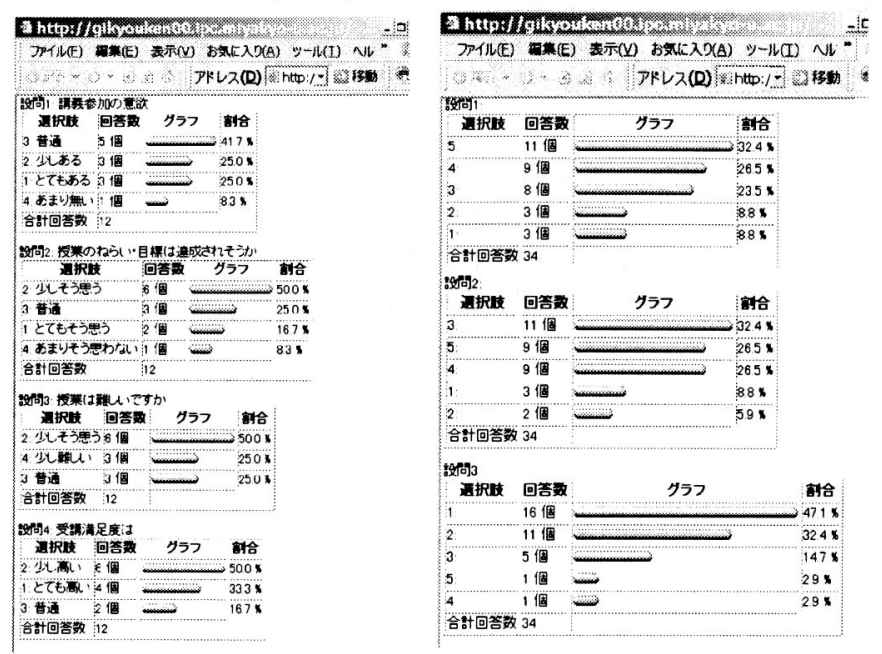

Fig 5(left) and 6(right)

A result of performance 


\section{Result}

Figure6 shows the result of the questionnaire in 'a study of teaching materials about technical Education' class. The numbered responses correspond to the intensity of their opinions: 5 means 'think so strongly' and 1 means don't think so strongly'.

Question1 asked about their level of motivation for the class. The mode was 3(not care) and affirmative answers accounted for 50 percent of all answers. Accordingly we realized that students had a relatively strong desire.

Question2 asked about purpose of this lecture. The result showed that the affirmative answers were overwhelming in the majority. As these results, we understood that the condition of the students was good.

Question3 asked about the difficulty of this lecture. The mode was 2 -it accounted for 50 percent of all answersthis told us that students felt this lecture was slightly difficult We could arrange and optimize the contents of a lecture and optimize incorporating these results. However we don't attempt to describe how this might occur. This system provides only some data from the students. After all it is necessary that the teacher has the skill to do so.

During the 'Information Processing' class we changed the way to teach according to students' computing skill or their knowledge. Formerly we let them raise their hands to show understanding. But the actual condition differed from the results. Some of them told us that they were embarrassed to raise their hands. Since this questionnaire system required only their cellular phone, we decided to put it to use.

The result is shown as figure 7. We create questions about the basic way to use 'MS-WORD'.

Questionl asked whether students could set margins exactly. This result showed that 58.9 percent of the participants answered with negative responses-meaning they could not do it well- and 17.6 percent answered with positive responses-meaning they could do it well. This result showed us that the students were poor at using the function.

Question2 asked whether students could use the

'Text Box' function. This result showed that 14.7 percent of the participants answered with negative responses and 53.0 percent answered with positive responses. This result showed us that more than half of the students could do it better than margin setting

Question3 asked whether students could change font size and font type. This result showed that 79.5 percent of the participants answered with positive responses and 5.8 percent of the participants answered with negative responses. Therefore we could realize that they were good at it.

This result had a direct interpretation. It indicated that we would have done better to teach them how to use the 'Text Box' and justify margins rather than worry about 'fonts'.

\section{CONCLUSION}

In this study, we developed a 'questionnaire system' to grasp students' actual conditions using e-mail on their cellular phones and subsequently evaluated it in two classes. We used this system and obtained satisfactory results. However final success depends on the result of teacher's skill. We know that there are a variety of classes in a university. We don't suggest that this system is always necessarily required. We consider this method and system as one of many possible methods.

This system could be extended wider than prior analyzer systems because of its facilitation, and the teacher could improve the value of their classes.

It became possible for us to collect students' questionnaires easier than traditional method using paper.

This system also can be used to gauge group intention.

In order to have students answer using a fixed format, we provide them with an explanation of the way to write their e-mails.

We will expand some functions; provide multiple answers and work in conjunction with a data base.

\section{REFERENCES}

[1] Fukushima Education Center Letter No.20, pp.59(1975)

[2] Study of Technical Education Method, Asakura Shoten, p.22(1993)

[3] ANDO, ABIKO, KINEFUTI: The Trial about ToolPractical Use of the Mobile Phone in Schools, Symposium on Mobile interactions and Navigations, pp.93-98(2003)

[4] ANDO, ABIKO, KINEFUTI: Development of the System to two-way interactions using a cellular phone, Japanese Society of Technology Education, p.60(2003) 